\title{
Prevention of Bleomycin-induced Pulmonary Fibrosis After Adenovirus-mediated Transfer of the Bacterial Bleomycin Resistance Gene
}

\author{
Phuong Lan Tran, ${ }^{*}$ Jérôme Weinbach,, Paule Opolon, ${ }^{\ddagger}$ Gustavo Linares-Cruz, ${ }^{\S}$ Jean-Paul Reynes, Anne Grégoire, ${ }^{*}$ \\ Eric Kremer, ${ }^{*}$ Henri Durand,,$\|$ and Michel Perricaudet ${ }^{*}$ \\ *UA1301-CNRS, Institut Gustave Roussy, 94805 Villejuif, France; ${ }^{\ddagger}$ Microbiologie et Génétique, Université Paul Sabatier, 31062 Toulouse, \\ France; ${ }^{\S}$ Pharmacologie Expérimentale, Institut de Génétique Moléculaire, 75010 Paris, France; and $\|_{\text {Laboratoires Cayla, } 31400 \text { Toulouse }}$
}

\begin{abstract}
A serious limitation in the use of the DNA-cleaving, antitumoral-antibiotic, bleomycin during chemotherapy is pulmonary toxicity. Lung injury induced by bleomycin is characterized by an increased deposition of interstitial extracellular matrix proteins in the alveolar wall that compromises respiratory function. Several drugs have been tested in animal models to prevent the pulmonary toxicity of bleomycin, but have not led to a useful clinical treatment because of their adverse effects on other tissues. We have shown that transgenic mice expressing Streptoalloteichus hindustanus (Sh) ble bleomycin resistance protein in pulmonary epithelial cells in the lungs are protected against bleomycin-induced toxicity in lungs. In the present study, we used intranasal administration by adenovirus-mediated gene transfer of the bleomycin resistance Sh ble gene to mouse lung for prevention of bleomycin-induced pulmonary fibrosis. We constructed recombinant adenoviruses Ad.CMVble and Ad.RSVble harboring the bleomycin resistance Sh ble gene under the control of the cytomegalovirus early promoter and the Rous sarcoma virus early promoter, respectively. Transgene expression was detected in epithelia of conducting airways and alveolar septa by immunostaining with a rabbit polyclonal antibody directed against the bleomycin resistance protein and persisted for the duration of drug treatment; i.e., up to $17 \mathrm{~d}$. No toxic effect was seen in adenovirus-treated mice. Pretreatment of mice with Ad.CMVble or Ad.RSVble completely prevented collagen deposition 42-133 d after bleomycin treatment, as measured by lung $\mathrm{OH}$-proline content. Histologic studies indicated that there was little or no lung injury in the adenovirus/bleomycin-treated mice compared with the bleomycin-treated mice. These observations may lead to new approaches for the prevention of bleomycin-induced pulmonary fibrosis. (J. Clin. Invest. 1997. 99:608-617.) Key words: bleomycin • pulmonary fibrosis - Streptoalloteichus hindustanus ble $\cdot$ gene transfer $\bullet$ mouse lung
\end{abstract}

\footnotetext{
Address correspondence to Phuong Lan Tran, INSERM U25, Faculté de Médecine Necker, 75730 Paris Cedex 15, France. Phone: 331 406156 69; FAX: 331406156 68; E-mail: pl.tran@necker.fr

Received for publication 12 March 1996 and accepted in revised form 5 December 1996.
}

J. Clin. Invest.

(C) The American Society for Clinical Investigation, Inc. 0021-9738/97/02/0608/10 \$2.00

Volume 99, Number 4, February 1997, 608-617

\section{Introduction}

One of the major problems generated from the increasing use of antineoplastic agents in chemotherapeutic treatments is pulmonary fibrosis, a chronic and potentially lethal response caused by many of these drugs (1). Bleomycin, a cytotoxic glycopeptide isolated from Streptomyces verticillius strain B-80-22 (2), is a highly useful chemotherapeutic agent used in the treatment of testicular carcinomas, malignant lymphomas, and certain squamous cell carcinomas without substantial bone marrow toxicity (3-6). The development of lung disease is the major dose-limiting side effect of this drug. The overall incidence of clinically apparent toxicity is $10 \%$, with a $1 \%$ incidence of lethality (7). Bleomycin produces lung parenchyma injury and interstitial fibrosis in man (8) and a similar condition in animal models (9). Histologic studies of human and animal lung have demonstrated evidence of injury to a variety of cell types, including a denuding of the vascular basement membrane. Interstitial fibrosis is ultimately characterized by increased deposition of extracellular matrix proteins in the alveolar wall, which compromises pulmonary function (10). The mechanism underlying the pathogenesis of the disease is still unclear. Several factors have been shown to influence the accumulation of interstitial extracellular matrix in the lung (11-16). Lazo and Humphreys (17) have also suggested that the lack of bleomycin hydrolase activity in the lung may contribute to the development of bleomycin-induced pulmonary fibrosis.

Data from mechanistic studies of bleomycin-induced pulmonary fibrosis in animal models have led to attempts to inhibit the initiation and progression of drug-induced pulmonary fibrosis. Treatment of mice with anti-CD11 antibodies (18) or antibodies to TGF $\beta$ (19) prevented collagen accumulation in lung after bleomycin treatment. Recombinant human soluble TNF receptor (20) was effective in preventing the development of bleomycin-induced pulmonary toxicity, and also reduced the amount of preestablished fibrosis. These approaches provided a better understanding of the pathogenesis of bleomycin-induced pulmonary fibrosis, but have not developed into a widely used clinical treatment, primarily because of the adverse effects of the above-mentioned agents in other tissues.

In the search for factors that could antagonize and reduce the bleomycin toxicity in lungs, two proteins were considered; the bleomycin hydrolase gene that encodes a cathepsinlike proteinase is in the process of being cloned, and Drocourt et al. (21) have cloned and expressed in Escherichia coli a Streptoalloteichus hindustanus $(\mathrm{Sh})^{1}$ ble gene that confers resistance to

1. Abbreviations used in this paper: $\mathrm{BRP}$, bleomycin resistance protein; CMV, cytomegalovirus; i.n., intranasal route; pfu, plaque forming units; RSV, Rous sarcoma virus; Sh, Streptoalloteichus hindustanus. 
phleomycin and its derivative, bleomycin. Sh ble gene encodes a nontoxic bleomycin resistance protein (BRP), which is a bleomycin binding protein and prevents DNA strand breakage in vitro $(22,23)$. To test whether expression of BRP in lungs can interfere with bleomycin and prevent its toxic effects, Weinbach et al. (24) have generated transgenic mice expressing the Sh ble bleomycin resistance gene under control of the thymidine kinase promoter and polyoma enhancer. Expression of BRP in pulmonary epithelial cells in the lungs of transgenic mice renders lung epithelial cells resistant to the normally toxic bleomycin. These results prompted us to use a recombinant adenovirus to transfer Sh ble to pulmonary epithelial cells. Adenovirus-mediated gene transfer provides a means of high-efficiency gene transfer in vitro $(25,26)$ and in vivo $(27-29)$. Recombinant adenoviruses are currently used in several gene therapy trials of lung disease (27) and other genetic disorders (30-32).

We subcloned Sh ble under the control of cytomegalovirus (CMV) early promoter or Rous sarcoma virus (RSV) early promoter in an adenovirus vector (33), and produced the recombinant adenoviruses, Ad.CMVble and Ad.RSVble, respectively. Ad.CMVble and Ad.RSVble were administered to C57BL/6 mice by intranasal (i.n.) route before intraperitoneal treatment with bleomycin. Initially, gene transfer was assessed using Ad.CMV $\beta$-gal, which codes for a nuclear-targeted $\beta$-galactosidase, and Ad.CMVble. The effect of BRP on pulmonary fibrosis elicited in mice by bleomycin was studied. The fibrotic process was evaluated by monitoring lung $\mathrm{OH}$-proline content, a convenient index of collagen deposition, and histologic examination of the pulmonary morphology. Our results show a protective effect of BRP against the drug toxicity in lungs of bleomycin-treated mice. Both viruses, Ad.CMVble and Ad.RSVble, were equally efficient at varying doses in vivo in our experimental conditions. This suggests that lung administration of a recombinant adenovirus expressing BRP could be a useful preventive treatment before antineoplastic treatment with bleomycin.

\section{Methods}

Cell culture and selection of transfected cells. Human embryonic kidney cell line 293 (CRL 1573; American Type Culture Collection, Rockville, MD) (34) was grown in minimal essential medium (MEM; GIBCO BRL, Gaithersburg, MD) containing 10\% FCS, 2 mM glutamine, $50 \mathrm{U} / \mathrm{ml}$ penicillin, and $50 \mu \mathrm{g} / \mathrm{ml}$ streptomycin. Hamster pulmonary fibroblastic DC3-F (gift from Dr. J. Belehradek, Institut Gustave Roussy) and HeLa cells were grown in Dulbecco's modified Eagle's medium (DMEM; GIBCO BRL) with supplements as above.

To test the biological activity of plasmids harboring Sh ble, DC3-F cells were used for transfection experiments because they were easier to handle in selection protocols than Hela cells. Transfection experiments were performed by calcium phosphate precipitation with $10 \mu \mathrm{g}$ of plasmid DNA, pAd.CMVble, or pAd.RSVble in 6-cm plates containing $5 \times 10^{5}$ cells. Phleomycin resistance cells were selected in medium containing $40 \mu \mathrm{g} / \mathrm{ml}$ of phleomycin, as described (35). Selected colonies were expanded and cultured with $20 \mu \mathrm{g}$ of phleomycin for analysis.

Construction of recombinant plasmids and adenoviruses. pAd.CMVnlacZ was constructed by replacing the cassette "RSVlacZ" in pAd.RSV $\beta$-gal with a cassette containing $C M V n l a c Z$, including an SV40 polyadenylation signal. pAd.RSV $\beta$-gal was digested with XbaIKpnI. pKS.CMVnlacZ was constructed by inserting lac $Z$ including a nuclear localization signal in the restriction sites EcoRI and XhoI of pKS.CMV containing the cytomegalovirus early promoter and an
SV40 polyadenylation signal. The cassette "CMVnlacZ" was isolated after digestion of pKS.CMVnlacZ with SpeI and KpnI. pAd.RSV $\beta$ gal and Ad.RSV $\beta$-gal have been previously described (36). pAd.RSVble was constructed by ligating a NarI-BglII fragment containing Sh ble from pUT614 (Cayla, Toulouse, France) and the ClaI-BglII portion of pAd.RSVnlacZ/ble, a plasmid coding for a $\beta$-galactosidase and BRP fusion protein. pAd.RSVnlacZ/ble was constructed by inserting in pAd.RSV $\beta$-gal, digested with EcoRV, the blunted EcoRVClaI fragment containing a portion of lac $Z$ fused to ble obtained from pUT598 (Cayla). pAd.CMVble was derived from pAd.RSVble by inserting into the XbaI-RsrII restriction sites of pAd.RSVble the digested fragment XbaI-RsrII from pZeoSV1 (Cayla) containing the complete cassette, including the CMV promoter and ble.

All the recombinant adenoviruses were generated by homologous recombination (36) between Ad $d l 324$ DNA, an adenovirus type 5 derivative with a deletion in the E1 and E3 regions, and the described plasmids. Infectious viruses were purified by plaques, and recombinant adenoviruses were tested for ble or $\beta$-gal expression. All recombinant viruses were propagated in 293 cells and purified by double cesium chloride density gradient ultracentrifugation. Titers of the viral stocks were determined by plaque assay on 293 cells.

Immunodetection by Western blot and immunofluorescence. Transfected phleomycin resistance DC3-F and HeLa cells infected, at an moi of 1,000, with either Ad.RSVble or Ad.CMVble for $24 \mathrm{~h}$, were harvested, washed once in PBS, suspended in electrophoresis buffer sample, and placed in boiling water for $10 \mathrm{~min} .10 \mu \mathrm{l}$ of cell extract containing $4 \times 10^{4}$ adenovirus-infected HeLa or transfected DC3-F cells were loaded per lane on a $15 \%$ polyacrylamide gel for electrophoresis according to Laemmli (37). Electrophoretic transfer to nitrocellulose (BA 83; Schleicher and Schuell, Inc., Keene, NH) was performed on a semidry apparatus (Sammy dry; Schleicher and Schuell) for $30 \mathrm{~min}$ at room temperature at $1.5 \mathrm{~mA} / \mathrm{cm}^{2}$. After preabsorption in PBS $/ 0.1 \%$ Tween 20 (PBST) supplemented with 5\% BSA, the filter was incubated with rabbit polyclonal anti-BRP antibody (Cayla) at a dilution of 1:1,000 for $1 \mathrm{~h}$ at room temperature. To reduce nonspecific adsorption of rabbit polyclonal antibody to cellular proteins, the polyclonal antibody was preadsorbed at $4^{\circ} \mathrm{C}$ for $30 \mathrm{~min}$ to an acetone-powdered DC3-F or Hela cells. The filter was washed three times with PBST and incubated with peroxydase-linked swine antirabbit IgG (Amersham Corp., Arlington Heights, IL) at a dilution of 1:10,000 for $45 \mathrm{~min}$ at room temperature. After washing with PBST, the filter was incubated with chemiluminescence reagents (DuPontNEN, Boston, MA) and exposed to film (Fuji Photo Film Co., Tokyo, Japan).

Processing of cells for immunofluorescence was done according to Tran and Deugnier (38). Briefly, adenovirus-infected HeLa cells, grown on Lab-Tek chamber slides (NUNC Inc., Naperville, IL), were washed with PBS, and after fixation for $30 \mathrm{~min}$ in $3.7 \%$ formaldehyde $/ 1 \%$ methanol, at room temperature, were labeled with the primary rabbit polyclonal anti-BRP antibody, diluted 1:100 in PBS containing $0.1 \%$ FCS for $45 \mathrm{~min}$ at $37^{\circ} \mathrm{C}$. After washing, cells were incubated with 1:100 of fluorescein-conjugated goat anti-rabbit IgG for $30 \mathrm{~min}$ at $37^{\circ} \mathrm{C}$. The slides were washed twice with PBS and cell nuclei were labeled with propidium iodide $(1 \mu \mathrm{g} / \mathrm{ml})$ for $2 \mathrm{~min}$. Control cells were treated with fluorescent antibody alone.

Animals and treatment. All animal experiments were performed according to guidelines set by the Institut Gustave Roussy. Studies were carried out with 4-wk-old female C57BL/6 mice weighing 15-16 g, from Janvier (Orléans, France). Table I depicts experimental designs of the three independent studies. Mice were randomly assigned in various groups in each study. Administration of the adenovirus vectors was achieved by i.n. administration in $30 \mu \mathrm{l}$ of sterile PBS on day 0 . All doses administered are indicated for each group (Table I). Bleomycin (bleomycin sulfate; Roger Bellon, France) diluted in saline buffer was intraperitoneally injected in five aliquots of $40 \mathrm{mg} / \mathrm{kg}$ on days $3,7,10,14$, and 17 . In each study, control mice received saline buffer by the i.n. $(30 \mu l)$ and/or i.p. $(160 \mu l)$ route. In the first study, we used recombinant Ad.CMVble and Ad.CMV $\beta$-gal to assess the effi- 


\begin{tabular}{|c|c|c|c|c|c|c|c|c|}
\hline \multirow[b]{2}{*}{ Study } & \multirow[b]{2}{*}{$\begin{array}{l}\text { Number of } \\
\text { animals }\end{array}$} & \multicolumn{3}{|c|}{ Virus } & \multicolumn{3}{|c|}{ Bleomycin } & \multirow[b]{2}{*}{$\begin{array}{c}\text { Time of } \\
\text { evaluation } \\
\text { (days) }\end{array}$} \\
\hline & & Vector & $\begin{array}{l}\text { Schedule day } \\
\text { (i.n.) }\end{array}$ & $\begin{array}{l}\text { Total dose } \\
\quad(\mathrm{pfu})\end{array}$ & $\begin{array}{l}\text { Optimal dose } \\
(\mathrm{mg} / \mathrm{kg}) \\
\text { per injection }\end{array}$ & $\begin{array}{l}\text { Schedule day } \\
\text { (i.p.) }\end{array}$ & $\begin{array}{l}\text { Total dose } \\
(\mathrm{mg} / \mathrm{kg})\end{array}$ & \\
\hline \multirow[t]{3}{*}{1} & 8 & Saline & 0 & - & - & - & - & $3,7,10,17$ \\
\hline & 8 & Ad.CMVble & 0 & $10^{9}$ & - & - & - & $3,7,10,17$ \\
\hline & 8 & Ad.CMVßgal & 0 & $10^{9}$ & - & - & - & $3,7,10,17$ \\
\hline \multirow[t]{6}{*}{2} & 6 & Saline & 0 & - & Saline & $3,7,10,14,17$ & - & 60 \\
\hline & 6 & Saline & 0 & - & 40 & $3,7,10,14,17$ & 200 & 60 \\
\hline & 6 & Ad.RSVble & 0 & $10^{9}$ & Saline & $3,7,10,14,17$ & - & 60 \\
\hline & 6 & Ad.RSVble & 0 & $10^{9}$ & 40 & $3,7,10,14,17$ & 200 & 60 \\
\hline & 6 & Ad.RSVßgal & 0 & $10^{9}$ & Saline & $3,7,10,14,17$ & - & 60 \\
\hline & 6 & Ad.RSVßgal & 0 & $10^{9}$ & 40 & $3,7,10,14,17$ & 200 & 60 \\
\hline \multirow[t]{10}{*}{3} & 8 & Saline & 0 & - & Saline & $3,7,10,14,17$ & - & 70,133 \\
\hline & 10 & Saline & 0 & - & 40 & $3,7,10,14,17$ & 200 & 70,133 \\
\hline & 8 & Ad.CMVble & 0 & $10^{9}$ & Saline & $3,7,10,14,17$ & - & 70,133 \\
\hline & 10 & Ad.CMVble & 0 & $10^{9}$ & 40 & $3,7,10,14,17$ & 200 & 70,133 \\
\hline & 8 & Ad.RSVble & 0 & $10^{9}$ & Saline & $3,7,10,14,17$ & - & 70,133 \\
\hline & 10 & Ad.RSVble & 0 & $10^{9}$ & 40 & $3,7,10,14,17$ & 200 & 70,133 \\
\hline & 4 & Ad.CMVßgal & 0 & $10^{9}$ & Saline & $3,7,10,14,17$ & - & 70 \\
\hline & 4 & Ad.CMVßgal & 0 & $10^{9}$ & 40 & $3,7,10,14,17$ & 200 & 70 \\
\hline & 4 & Ad.RSVßgal & 0 & $10^{9}$ & Saline & $3,7,10,14,17$ & - & 70 \\
\hline & 4 & Ad.RSV $\beta$ gal & 0 & $10^{9}$ & 40 & $3,7,10,14,17$ & 200 & 70 \\
\hline
\end{tabular}

Treatment schedule of each group of mice is depicted.

cacy of in vivo gene transfer. Two mice from each group were killed on days $3,7,10$, and 17. Both lungs were removed and processed for either X-gal or immunohistochemical staining with the polyclonal rabbit anti-BRP antibody. In the second study, six groups of mice were treated by i.n. administration of one dose of Ad.RSVble \pm bleomycin or Ad.RSV $\beta$-gal \pm bleomycin. All mice were killed on day 60 . The right lung was prepared for $\mathrm{OH}$-proline assay and the left lung for histologic examination. In the third study, various combinations including Ad.CMVble \pm bleomycin, Ad.CMV $\beta-$ gal \pm bleomycin, Ad.RSVble \pm bleomycin, and Ad.RSV $\beta$-gal \pm bleomycin were performed. Half of the mice in each group were killed on day 70 , and the second half on day 133 for evaluation as indicated in the third study. All mice were monitored regularly and received food and water ad libitum. The treatment with bleomycin induces some morbidity manifested by a loss in body weight. The mortality observed was low, ranging among 0 and $10 \%$ in the three studies.

Histology and immunohistochemistry. Expression of $\beta$-gal and BRP was evaluated in mice, after a single i.n. administration with either $10^{9}$ plaque forming units (pfu) of Ad.CMV $\beta$-gal or $10^{9} \mathrm{pfu}$ of Ad.CMVble at days 3, 7, 10, and 17 (see Table I). The nasal mucosa, superior and inferior trachea, and right and left lungs were removed and embedded in O.C.T. (Tissue-Tek; Miles Laboratories, Inc., Elkhart, IN), immediately frozen in 2-methyl butane cooled by liquid nitrogen, and stored in liquid nitrogen. Cryosections $(10 \mu \mathrm{m})$ of the different organs were processed by postfixing in $0.37 \%$ formaldehyde $/ 0.2 \%$ glutaraldehyde in PBS, stained with X-gal (5-bromo-4chloro-3-indolyl- $\beta$-D-galactosidase), and counterstained with hematoxylin/eosin as described (36). Morphological evaluation of the fibrotic response was performed on left lungs of control and treated mice at days 60, 70, and 133. Briefly, the left lung of each mouse was fixed in AFA (Carlo Erba, Italy), dehydrated by two passages through graded alcohol and xylene, and were then embedded in paraffin. Sagittal sections, 5- $\mu \mathrm{m}$ thick, were cut and stained with hematoxylineosin-safran and Masson trichrome for identification of lesions. Slides were examined with an Axiophot transmission microscope (Carl Zeiss, Inc., Thornwood, NY).

Immunohistochemical detection of BRP in lungs was optimized using a fluorescent tyramide substrate for peroxidase (39). Briefly, cryosections $(5 \mu \mathrm{m})$ of the right and left lungs were postfixed in $4 \%$ (wt/vol) paraformaldehyde in PBS, $\mathrm{pH} 7.4$, for $15 \mathrm{~min}$ at room temperature. The sections were washed twice with PBS containing $0.1 \%$ triton X-100 and 2\% BSA and covered with $0.1 \mathrm{M}$ glycine in PBS for $15 \mathrm{~min}$. They were then incubated overnight with the primary rabbit polyclonal anti-BRP antibody diluted 1/100. After three washings with PBS/triton X-100/BSA, they were incubated with a peroxidaseconjugated goat anti-rabbit IgG for $1 \mathrm{~h}$ at room temperature. Sections were washed and incubated with fluorescein-conjugated tyramide for $10 \mathrm{~min}$ at room temperature at a dilution of $1 / 1,000$ in $0.2 \mathrm{M}$ Tris- $\mathrm{HCl}, 10 \mathrm{mM}$ imidazole, $0.01 \% \mathrm{H}_{2} \mathrm{O}_{2}$, $\mathrm{pH}$ 8.8. They were then washed two times with PBS/triton X-100/BSA, and cell nuclei were labeled with iodide propidium $(1 \mu \mathrm{g} / \mathrm{ml})$ for $2 \mathrm{~min}$. Slides were washed thoroughly and mounted in Glycergel. Observations were carried out with an MRC-600 confocal scanning laser microscope (Bio-Rad Laboratories, Hertfordshire, UK), using the Comos software package (Bio-Rad Laboratories) as described (40).

Hydroxyproline assay. Lung $\mathrm{OH}$-proline content was assayed as previously described with modifications (41). Briefly, the right lung of each mouse was dissected free of major bronchi and the lobes were minced in 1-mm-thick pieces. They were hydrolyzed in $2 \mathrm{ml}$ of $6 \mathrm{~N}$ $\mathrm{HCl}$ at $110^{\circ} \mathrm{C}$ overnight in tightly capped tubes to liberate amino acids. The resultant hydrolysate was neutralized with $2 \mathrm{ml}$ of $6 \mathrm{~N}$ $\mathrm{NaOH}$, and extracted with phenol-chloroform-isoamylalcohol to clarify the aqueous phase. The extracts were filtered through $0.45-\mu \mathrm{m}$ membrane (minisart; Sartorius, Lyons, France), adjusted to $\mathrm{pH} 6-8$ and diluted to $20 \mathrm{ml}$. OH-proline concentration was then determined colorimetrically and expressed as weight (micrograms) of $\mathrm{OH}$-proline per right lung. Purified OH-proline was used as a standard. OH-proline content per lung was used to avoid the artifactual lowering of the val- 
Table II. Lung OH-Proline Content After Pretreatment With Recombinant Ad.RSVble or Ad.RSVB-gal and Treatment With Bleomycin

\begin{tabular}{|c|c|c|c|c|}
\hline \multirow{2}{*}{$\begin{array}{l}\text { Treatment } \\
\text { Ad }\end{array}$} & \multirow[b]{2}{*}{ Bleomycin } & \multicolumn{3}{|c|}{ OH-proline ( $\mu$ g/right lung) } \\
\hline & & Day 60 & Day 70 & Day 133 \\
\hline- & - & $177.8 \pm 15.3$ & $175.2 \pm 10.1$ & $173.1 \pm 8.8$ \\
\hline- & + & $264.2 \pm 28.1^{*}$ & $279.4 \pm 11.3^{*}$ & $290.4 \pm 17.5^{*}$ \\
\hline Ad.RSVble $\left(10^{9} \mathrm{pfu}\right)$ & - & $186.3 \pm 11.2$ & $187.8 \pm 7.1$ & $191.3 \pm 10.4$ \\
\hline Ad.RSVble $\left(10^{9} \mathrm{pfu}\right)$ & + & $197.1 \pm 19.4^{\ddagger}$ & $188.3 \pm 4.0^{\ddagger}$ & $196.1 \pm 6.6^{\ddagger}$ \\
\hline Ad.RSV $\beta$-gal $\left(10^{9} \mathrm{pfu}\right)$ & - & $182.7 \pm 8.4$ & $191.0 \pm 8.6$ & nd \\
\hline Ad.RSV $\beta$-gal $\left(10^{9} \mathrm{pfu}\right)$ & + & $241.5 \pm 10.4^{*}$ & $268.4 \pm 21.8^{*}$ & nd \\
\hline
\end{tabular}

Mice were pretreated by i.n. instillation of Ad.RSVble on day 0 with a single dose of $10^{9} \mathrm{pfu}$ of Ad.RSVble. Control mice received saline buffer or Ad.RSV $\beta$-gal $\left(10^{9} \mathrm{pfu}\right)$. After $3 \mathrm{~d}$, bleomycin treatment started by injections of $5 \times 40 \mathrm{mg} / \mathrm{kg}$ each i.p., twice weekly for $2 \mathrm{wk}$. The different groups of mice were killed as indicated. Each OH-proline value is the mean \pm SEM obtained from the right lung. ${ }^{*} P<0.05,{ }^{*} P<0.1$. nd, not determined.

ues in bleomycin-treated animals. The values were reported as the mean \pm SEM.

The results from lung OH-proline content (Table II) and evaluation of fibrotic responses on lung sections (Table III) were examined by analysis of variance using nonparametric statistics with KruskalWallis test (Program 3S; BMPD Statistical Software, Inc., Los Angeles, CA). The difference in OH-proline content of adenovirus/bleomycin-treated mice vs. saline-, adenovirus-, and bleomycin-treated mice, as well as bleomycin-treated mice vs. saline-treated mice was statistically significant, $0.05<P<0.1$. The difference in fibrotic responses in lung sections between the appropriate groups was also statistically significant, $P<0.0001$.

Table III. Effect of BRP on Lungs of Bleomycin-treated Mice: Morphologic Scoring

\begin{tabular}{|c|c|c|c|c|c|c|}
\hline \multirow[b]{2}{*}{ Treatment } & \multirow[b]{2}{*}{$\begin{array}{l}\text { Day of } \\
\text { killing }\end{array}$} & \multicolumn{5}{|c|}{ Histology } \\
\hline & & $\begin{array}{l}\text { Number } \\
\text { of animals }\end{array}$ & $\mathrm{F}_{-}$ & $\mathrm{F}_{ \pm}$ & $\mathrm{F}_{+}$ & $\mathrm{F}_{++}$ \\
\hline \multirow[t]{3}{*}{ Control } & 60 & 2 & 2 & - & - & - \\
\hline & 70 & 4 & 3 & 1 & - & - \\
\hline & 133 & 4 & 4 & - & - & - \\
\hline \multirow[t]{3}{*}{ Bleomycin* } & 60 & 6 & - & - & 1 & 5 \\
\hline & 70 & 4 & - & 1 & 1 & 2 \\
\hline & 133 & 4 & - & - & 2 & 2 \\
\hline \multirow[t]{3}{*}{ Ad.RSVble } & 60 & 11 & 11 & - & - & - \\
\hline & 70 & 9 & 7 & 2 & - & - \\
\hline & 133 & 9 & 9 & - & - & - \\
\hline \multirow{3}{*}{$\begin{array}{l}\text { Ad.RSVble + } \\
\text { bleomycin* }\end{array}$} & 60 & 11 & 10 & 1 & - & - \\
\hline & 70 & 10 & 5 & 4 & 1 & - \\
\hline & 133 & 7 & 4 & 3 & - & - \\
\hline \multirow[t]{2}{*}{ Ad.RSV $\beta$-gal } & 60 & 5 & 5 & - & - & - \\
\hline & 70 & 3 & 3 & - & - & - \\
\hline \multirow{2}{*}{$\begin{array}{c}\text { Ad.RSV } \beta \text {-gal + } \\
\text { bleomycin* }\end{array}$} & 60 & 5 & - & - & 1 & 4 \\
\hline & 70 & 3 & - & - & 3 & - \\
\hline
\end{tabular}

Mice were pretreated on day 0 by i.n. instillation with a single dose of $10^{9} \mathrm{pfu}$ of Ad.RSVble. Control mice received saline buffer or Ad.RSV$\beta$-gal $\left(10^{9} \mathrm{pfu}\right)$. After $3 \mathrm{~d}$, bleomycin treatment started by injections of $5 \times$ $40 \mathrm{mg} / \mathrm{kg}$ each i.p., twice weekly for $2 \mathrm{wk}$. The different groups were killed as indicated. Lesions were defined as $F_{-}$, absence of lesion; $F_{ \pm}$, occasional small localized subpleural foci; $\mathrm{F}_{+}$, thickening of interalveolar septa and subpleural foci; and $\mathrm{F}_{++}$, thickened continuous subpleural fibrous gangue and interalveolar septa. ${ }^{*} P<0.0001$.

\section{Results}

In vitro transfer and expression of the Sh ble in DC3-F and $\mathrm{HeL}$ a cells. In vitro biologic activity of BRP was assessed by transfection of pAd.CMVble and pAd.RSVble into DC3-F cells. Selection of phleomycin resistance DC3-F cells with 40 $\mu \mathrm{g}$ of phleomycin for $15 \mathrm{~d}$ yielded phleomycin resistance colonies at $10^{-5}$ frequency per $10 \mu \mathrm{g}$ DNA (see Methods), comparable with those previously reported by Mulsant et al. (35). Western blot analysis of phleomycin resistance cells showed a strong band at $13.7 \mathrm{kD}$ corresponding to BRP expression (not shown). After infection of Hela cells with Ad.CMVble at an moi of 1,000 for $24 \mathrm{~h}$, expression of BRP was analyzed by Western blot and revealed an intense band corresponding to monomeric BRP (Fig. 1, lane 2), as compared with purified BRP (Fig. 1, lane 1). A nonspecific adsorption of the polyclonal antibody to cellular proteins transduced by Ad.CMVble was observed, particularly a band located at $18 \mathrm{kD}$ (Fig. 1, lanes 2 and 3).

Subcellular localization of BRP in HeLa cells infected by Ad.CMVble was analyzed using a rabbit polyclonal anti-BRP antibody. Confocal scanning laser microscopy displayed substantial cytoplasmic fluorescence accompanied by a bright accumulation of fluorescence around the propidium iodidelabeled nucleus (Fig. 2 A). Analysis of confocal images showed that BRP signals were compartmentalized in the cytoplasm (not shown). A pattern of a perinuclear distribution suggests a localization of BRP in the Golgi and endoplasmic reticulum (42). We have not seen nuclear localization of BRP in contrast with the observation reported by Calmels et al. (43).

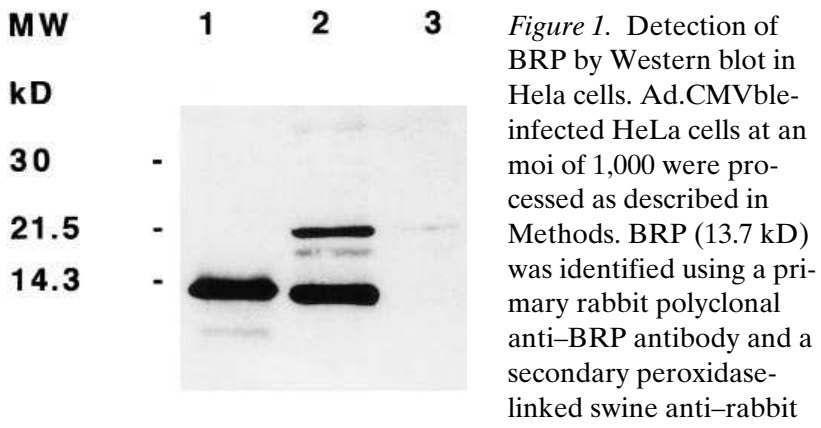

IgG. Lane 1, purified BRP (100 ng); lane 2, lysate from Ad.CMVbleinfected HeLa cells; and lane 3, lysate from control HeLa cells. 

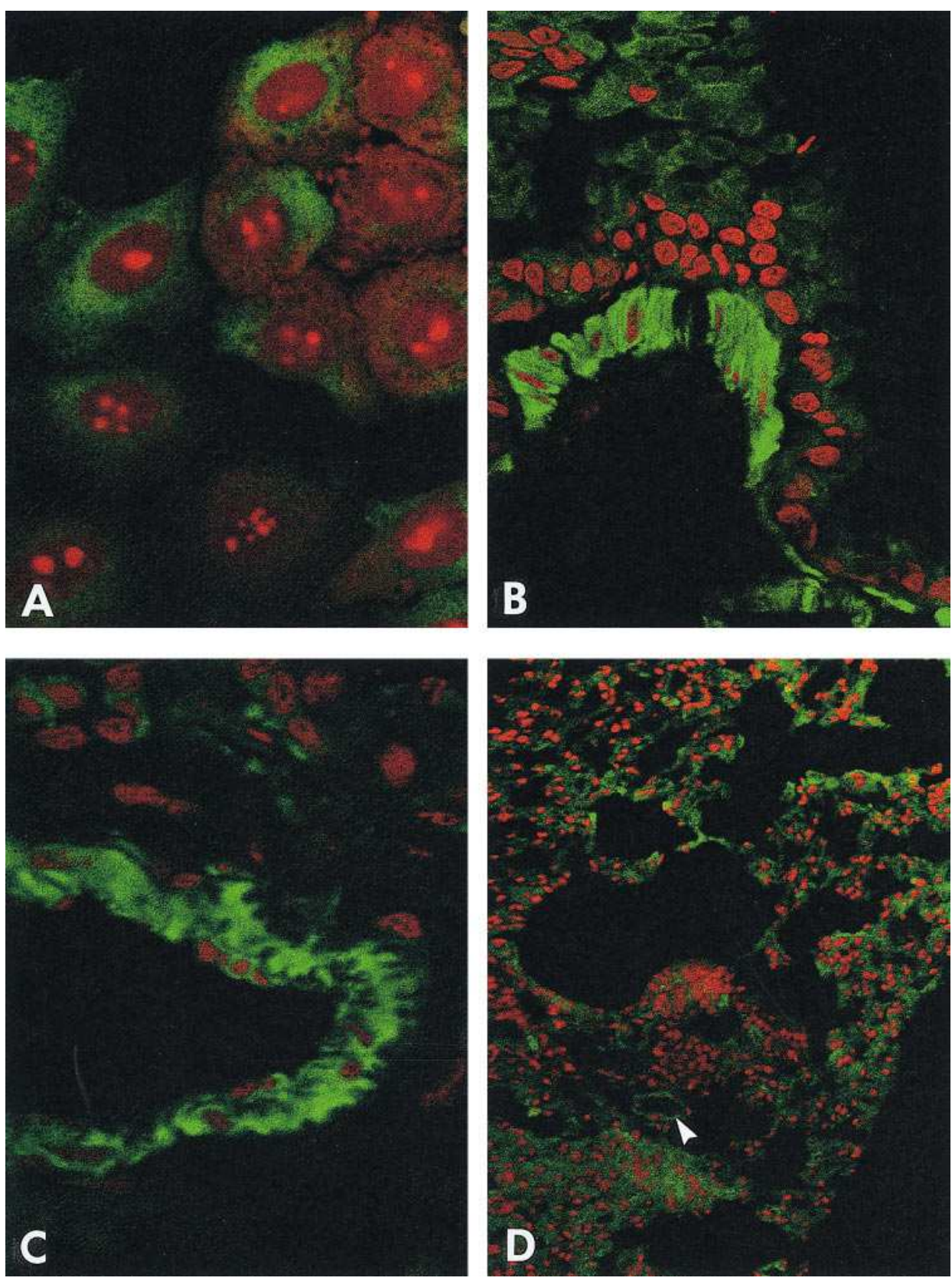

Figure 2. In vitro expression of BRP in HeLa cells and in vivo distribution and expression of BRP after i.n. administration of Ad.CMVble to C57BL/6 mice. Immunocytochemical localization of BRP was performed on adenovirus-infected Hela cells as described in Methods. Ad.CMVble $\left(10^{9} \mathrm{pfu}\right)$ was administered to mice by i.n. instillation. After $17 \mathrm{~d}$, right and left lungs were removed and processed as described in Methods. Observations were carried out with an MRC-600 confocal scanning laser microscope. (A) Cytoplasmic and perinuclear localization of BRP in Ad.CMVble-infected Hela cells. Note the labeling of nucleolus by propidium iodide. (B) An optical section of a large bronchus showing ciliated cells strongly labeled above a propidium iodide-labeled chondrocyte nucleus layer. $(C)$ An optical section of bronchiolar structure showing a clear apical labeling of epithelial cells. $(D)$ Pulmonary parenchyma showing distribution of BRP in epithelial cells lining the alveolar walls and small bronchioles (arrowhead). Calibration: 5.4 pixels $/ \mu \mathrm{m}$.
In vivo gene transfer and detection of $\beta$-galactosidase and $B R P$ in the airway epithelium. Examination of adenovirus-mediated transfer and expression of lac $Z$ and Sh ble in mice was performed after X-gal staining on fragments of the nasal mucosa, superior and inferior trachea, and the right and left lungs, and after immunostaining of BRP with a rabbit polyclonal anti-BRP antibody on lungs of each mouse, respectively. $\beta$-Gal expression was found $(a)$ in the nasal mucosa, $(b)$ throughout the trachea, and $(c)$ the bronchi distal to the site of administration. In particular, $\beta$-gal expression was found in the conducting airway cells, including the nasal and tracheal ciliated cells, and unusually in the tracheal submucosal glands (not shown). In both right and left lung sections, patchy $\beta$-gal expression was detected on the epithelial surfaces of the large and small airways and terminal bronchioles and alveoli (not shown). The same observations in CD1 mice have been reported by Dong et al. (44). Expression of $\beta$-gal was detected up to $7 \mathrm{~d}$. In general, there was little evidence of inflammation in the lungs of mice that received adenoviral vectors by i.n. administration. However, in one case, a mild lymphocytic infiltration was observed (not shown).

Analysis by confocal scanning laser microscopy of lung sections immunostained with antibodies directed against BRP demonstrated specific expression of BRP in various structures. In contrast with $\beta$-gal expression, BRP was detected up to $17 \mathrm{~d}$ (i.e., throughout the period of bleomycin treatment), as shown by Fig. 2, B-D. A simultaneous double labeling with propidium iodide, which stains cell nuclei within tissue structures, showed that BRP was detected in the epithelial surfaces of the large and small airways and terminal bronchioles, as well as in the alveolar septa. Optical sections of a large bronchial structure showed ciliated cells strongly labeled by anti-BRP anti- 
body above a propidium iodide-labeled chondrocyte nuclear layer (Fig. 2 B). BRP expression was also distributed in epithelial cells of bronchiolar structures (Fig. $2 C$ ), and in alveoli and small bronchioles (Fig. $2 D$ ). As shown in Fig. 2, $B-D$, no nuclear signal was detected, consistent with our observations in adenovirus-infected Hela cells (Fig. $2 A$ ). Confocal images showed that BRP could be detected without attenuation, down to the deepest confocal plane inside each specimen (not shown).

Effect of BRP on the OH-proline content after in vivo Admediated gene transfer. To evaluate the efficiency of BRP to prevent the toxic effects of bleomycin, we designed a protocol of pretreatment of mice with recombinant adenoviruses $72 \mathrm{~h}$ before bleomycin treatment. Two independent experiments were undertaken. Mice were randomly assigned in various groups as depicted in Table I. In the treated groups, mice were infused by i.n. instillation with Ad.CMVble or Ad.RSVble. Control mice received either saline buffer, Ad.CMV $\beta$-gal, or Ad.RSV $\beta$-gal. Intraperitoneal administration of bleomycin started $72 \mathrm{~h}$ after i.n. administration of recombinant adenoviruses. To generate a reproducible and measurable fibrotic response, we increased the total dose of bleomycin to $200 \mathrm{mg} / \mathrm{kg}$ in contrast with the dose of $100 \mathrm{mg} / \mathrm{kg}$ frequently used (unpublished results and reference 24 ). In these experimental conditions, we observed after $42 \mathrm{~d}$ marked pulmonary lesions and a $50 \%$ increase in lung $\mathrm{OH}$-proline content vs. the control $(P<$ 0.05 ) (not shown). Bleomycin was intraperitoneally injected in five doses of $40 \mathrm{mg} / \mathrm{kg}$ twice weekly. This route of administration has been shown to be slightly less toxic than the intravenous route and caused minimal mortality (45). As expected, administration of bleomycin led to a $15-20 \%$ decrease in body weight. Weight loss occurred in all bleomycin-treated mice, whereas administration of adenovirus alone did not affect body weight (not shown).

The preventive effect of BRP to bleomycin toxicity in mouse lungs was studied under various conditions. The influence of BRP on changes of total lung collagen content, expressed as $\mathrm{OH}$-proline content, was examined in two independent studies using various doses of either Ad.CMVble or Ad.RSVble, as well as recording the duration of lung protection. Since our assays showed identical preventive effects on lung collagen deposition in mice pretreated with either Ad.CMVble or Ad.RSVble and treated with bleomycin, only data obtained from untreated-, bleomycin- and Ad.RSVble \pm bleomycin-treated mice, killed on days 60, 70, and 133 are shown in Table II. The mean value of $\mathrm{OH}$-proline content $(175.4 \pm 10.4 \mu \mathrm{g} /$ right lung) calculated from the three control values depicted the basal $\mathrm{OH}$-proline level (not indicated in Table II). The lung OH-proline content in bleomycintreated groups of mice was significantly increased with time as compared to control $(P<0.05)$. In contrast, in the Ad.RSVble \pm bleomycin-treated groups, the data showed that when mice were pretreated with Ad.RSVble, lung collagen deposition was prevented, compared with mice treated with bleomycin alone, or control groups of mice infused with Ad.RSV $\beta$-gal and treated with bleomycin $(P<0.1)$. No increased effect was noted after administration of recombinant adenovirus doses varying from $5 \times 10^{8}$ to $5 \times 10^{9}$ pfu per mouse. Therefore, in Table II, only the lung collagen content of untreated or bleomycin-treated mice infused once with a dose of $10^{9} \mathrm{pfu}$ of Ad.RSVble is depicted. The duration of protection against bleomycin toxicity in Ad.RSVble-treated mice was observed up to $133 \mathrm{~d}$ after bleomycin treatment (Table II).
In conclusion, BRP appeared to protect the adenovirustreated mice from toxic effects of bleomycin by preventing lung collagen deposition.

Effect of BRP: histologic evaluation. To provide a visual correlation to the quantitative $\mathrm{OH}$-proline data, we evaluated the extent of fibrotic lesions on lung sections stained by hematoxylin-eosin-safran and Masson trichrome by transmission microscopy. Administration of bleomycin by intraperitoneal injection did not lead to a rapid fibrosis. This observation has been previously reported (46). After $42 \mathrm{~d}$ (28 d after injection), the fibrotic damage in bleomycin-treated mice was mainly located in the subpleural regions. In our study, mice were killed from 42 to $133 \mathrm{~d}$ after bleomycin treatment. Fig. 3, $A-H$ shows light microscopic views of lung sections from control and treated mice killed at day 60, which were representative of one study. Histologic sections from control mice depicted normal lung structure and no pathologic changes (Fig. $3 A$ ). However, intranasal instillation of recombinant adenovirus induced a limited inflammatory response. Peribronchiolar and perivascular foci of inflammatory cells were observed (Fig. $3 \mathrm{~B}$ ). These foci were composed of predominantly alveolar macrophages. Polymorphonuclear leukocyte infiltrates were minimal or absent. Usually, the intensity of infiltrates diminished after $56 \mathrm{~d}$ (47), but in our study it persisted at least $60 \mathrm{~d}$ after viral infusion. Fig. 3, $C$ and $D$ displayed typical histologic lung lesions from bleomycin-treated mice, characterized by inflammation and fibrosis. In all lung sections where the fibrotic process was detected, septa of fibrosis were conspicuous in hematoxylineosin-safran staining. In some cases, Masson trichrome staining visualized collagen thickening of the septa. Although the epithelium of the bronchioles was still normal, a diffuse alveolitis was accompanied by interstitial edema in the alveolar wall and occasional thickening of the alveolar septa. The lesions contained increased numbers of alveolar macrophages and were occasionally invaded by lymphocytic infiltration and polymorphonuclear leukocytes (Fig. $3 C$ ). In the subpleural areas including edema, infiltrates of macrophages, and patchy foci of lymphocytes, fibrotic alteration was irregularly distributed, consistent with previous observations (9). Fig. 3, $E$ and $F$ shows a hemorrhagic alveolitis and an indication of fibrotic gangue. These morphologic changes were observed in lungs of the majority of bleomycin-treated mice killed at days 60, 70, and 133. In contrast, lung sections from mice pretreated with Ad.RSVble and treated with bleomycin (Fig. 3, $G$ and $H$ ) showed a thin pleural serosa with a single continuous layer of elastin, normal alveolar structure, and absence of lesions. The diffuse alveolitis and alterations caused by bleomycin in the parenchyma as well as fibrotic damages in the subpleural areas were absent. No detectable collagen staining, using specific Masson trichrome, was seen when compared with lung sections from bleomycin-treated mice (Fig. 3, $D$ and $H$ ). In some cases, occasional small inflammatory foci could be attributed to an inflammatory response to adenovirus, although all lungs from the adenovirus/bleomycin-treated groups of mice were generally of normal structure (not shown). Finally, Table III summarized scoring of lung morphologic changes as defined by the presence or absence of fibrotic lesions in the parenchyma and/ or in the subpleural region. For each time of evaluation, the total number of Ad.RSVble-treated mice in each group, at all doses, from the two independent studies was pooled. Mice partially or totally protected by BRP were as follows: (a) 19/28 mice showed no lung injury in Ad.RSVble/bleomycin groups. 

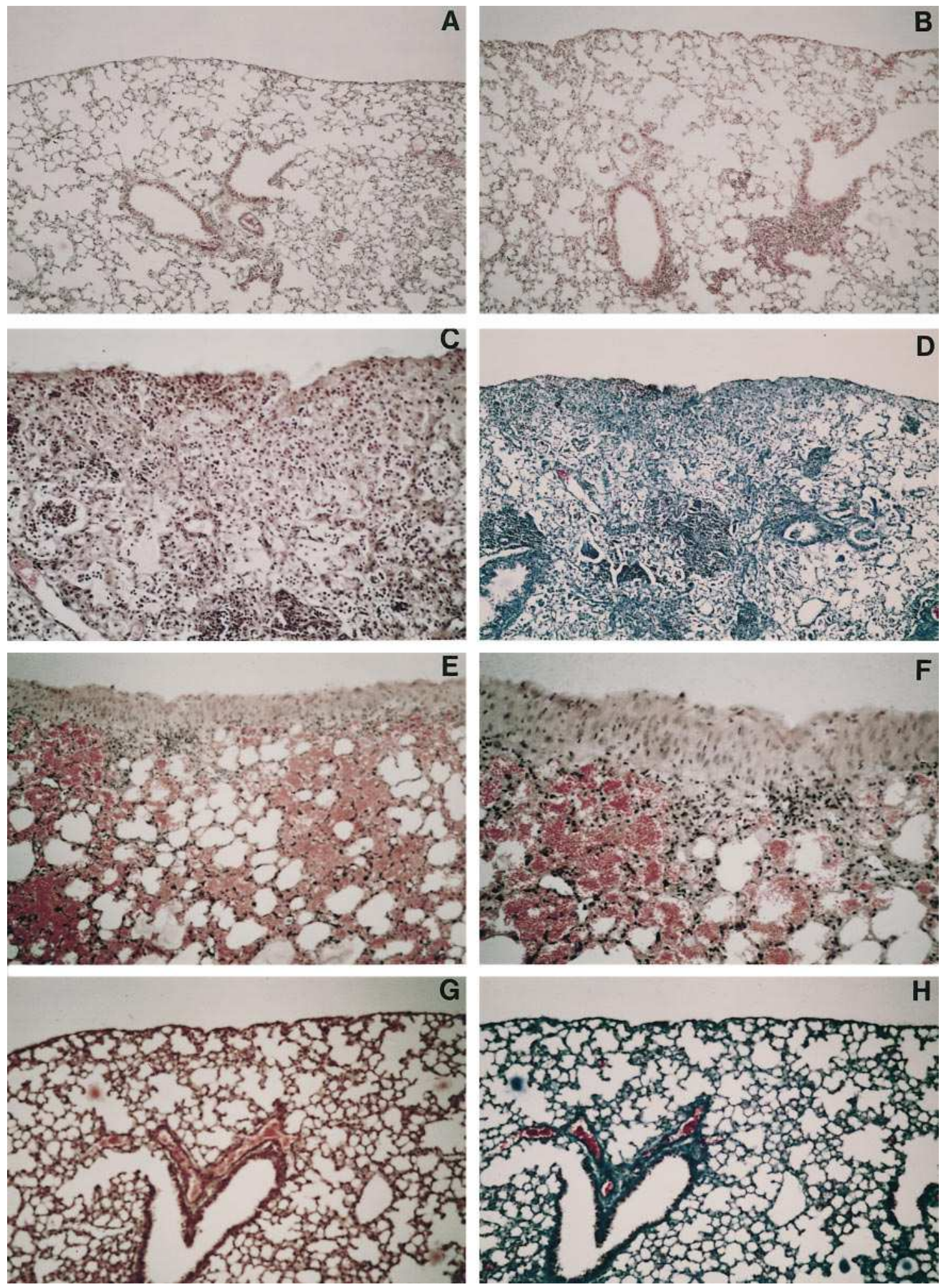

Figure 3. Histopathologic changes within the C56BL/7 mouse lung after treatment with bleomycin and/or in vivo i.n. administration of recombinant Ad.RSVble. Mice were treated with bleomycin or $10^{9} \mathrm{pfu}$ Ad.RSVble + bleomycin. Control mice received saline buffer or Ad.RSVble alone. All mice were killed at day 60. The left lung was removed and processed for histological examination. $(A)$ Control with normal alveolar structure $(200 \times)$. (B) Administration of Ad.RSVble $\left(10^{9} \mathrm{pfu}\right)$ alone: note peribronchiolar and perivascular inflammatory foci-invaded macrophages $(200 \times)$. $(C-F)$ Bleomycin treatment by injections of $5 \times 40 \mathrm{mg} / \mathrm{kg}$ each i.p., twice weekly for 2 wk. Note in $C$ the infiltrate of lymphocytes and macrophages $(200 \times)$. Collagen is stained by Masson trichrome in $D(100 \times)$. In this case, the intraparenchymal fibrosis is associated with the subpleural fibrosis. Note the fibrotic gangue in the subpleural region and hemorrhagic infiltrate in the alveolar spaces in $E(200 \times)$ and $F$ $(400 \times)$. $(G$ and $H)$ i.n. Instillation of Ad.RSVble $\left(10^{9} \mathrm{pfu}\right)$ on day 0 and followed on day 3 by bleomycin injections of $5 \times 40 \mathrm{mg} / \mathrm{kg}$ each i.p., twice weekly for 2 wk. Note the absence of bleomycin-induced parenchymal damage and normal alveolar structure $(G$ and $H, 200 \times)$. 
The remaining mice showed normal parenchyma structure with one or two occasional small localized subpleural foci. (b) In one case (1/28), a mouse received a dose of $2 \times 10^{9}$ pfu of Ad.RSVble, and a thickening of interalveolar septa and subpleural foci was recorded. In control groups of saline-treated mice or mice treated with recombinant adenovirus alone, lung lesions were low. When Ad.RSVble/bleomycin-treated mice were compared with control (saline-, bleomycin-, or $\beta$-gal/bleomycin-treated) mice, BRP showed a significant protective effect on bleomycin-induced toxicity $(P<0.0001)$. Thus, these results demonstrated that BRP was efficient in drastically decreasing the pneumopathy after cumulative administration of bleomycin.

\section{Discussion}

The use of bleomycin as a therapeutic agent in the treatment of cancer is limited by side effects that can result in pulmonary fibrosis. The hallmark of the disease is characterized by the increase of extracellular matrix proteins, notably collagens, associated with the growth of interstitial cells within the alveolar septa $(48,49)$. Current therapy of human pulmonary fibrosis with corticosteroids generally have little benefit. In animal models, various attempts designed to inhibit the initiation and progression of bleomycin-induced pulmonary fibrosis have not led to a useful clinical trial because of the adverse effects on lungs and other tissues by the agents tested (18-20).

The results presented here may lead to a new approach to prevent the development of bleomycin-induced pulmonary fibrosis. Our experiments provide strong support that the transfer of Sh ble via nasal droplet to the respiratory epithelium conferred protection against pulmonary fibrosis after bleomycin treatment. We have shown that there was good agreement between the two studies, using Ad.CMVble or Ad.RSVble, where both viruses were equally efficient in vivo under our conditions. No significant difference was observed in the lung collagen content between the Ad.CMVble/bleomycin- and Ad.RSVble/bleomycin-treated groups and control groups (not shown). A preventive treatment with a single dose of recombinant adenovirus before bleomycin treatment was sufficient to prevent collagen accumulation in the lungs (Table II). Treatment with recombinant adenovirus alone did not cause any clinically adverse effects, whereas this was not the case after bleomycin treatment alone. Lack of collagen deposition was also corroborated by histologic studies (Fig. 3). The absence of lung lesions supports the evidence that there was little or no lung injury in the Ad.RSVble/bleomycin groups compared with the bleomycin-treated group, and mice infused with Ad.RSV $\beta$-gal and treated with bleomycin (Table III). These findings were associated with the absence of stainable collagen in the lungs from Ad.RSVble/bleomycin-treated mice compared with bleomycin-, and Ad.RSV $\beta$-gal/bleomycin-treated mice (Fig. 3).

We demonstrated by immunostaining that BRP expression was localized in the epithelia lining the alveolar walls, the epithelial surfaces of the small and large bronchi, and terminal bronchioles (Fig. 2, B-D). A single dose of $10^{9}$ pfu of recombinant adenovirus may produce a sufficient level of BRP expression in lungs to prevent injury of bleomycin to the parenchyma and alveolar structures. Consequently, both the pathologic features of diffuse interstitial lung lesions, collagen accumulation and infiltration of inflammatory cells in the alveolar septa, were not found in lungs of BRP-treated mice (Fig. 3, $G$ and $H)$. As previously reported $(21,22)$, Sh ble encodes a nontoxic protein that protects DNA against damage caused by bleomycin, by sequestering the drug in a ratio 1:1 without metabolization. Lazo et al. (50) have reported that only a limited amount of bleomycin actually enters cells to produce lethal lesions. We demonstrated that after a single recombinant adenovirus dose, expression of BRP persisted for the duration of bleomycin treatment (up to $17 \mathrm{~d}$ ). Thus, a limited expression of BRP in the lungs would be sufficient to protect lung epithelial cells by decreasing local toxicity of bleomycin. A dose-response study is required to investigate whether the dose of recombinant adenovirus could be lowered to minimize inflammatory response to adenovirus vectors, while keeping the same efficacy in protecting lungs against injury of bleomycin.

The biochemical mechanism of induction of lung fibrosis still remains unclear. Lazo et al. (50) suggested that druginduced lung fibrosis is a multistep process. According to Adamson and Bowden (9), the earliest site of injury described after bleomycin treatment involves the endothelium of pulmonary arteries and veins, resulting in endothelial cell swelling and blebbing. The development of pulmonary lesions is then accompanied by infiltrates of plasma cells and lymphocytes. It will be of interest to analyze whether the protective effects of BRP would include protection of endothelial cells from injury indirectly due to bleomycin, as well as prevention of the sequential cellular damage before fibrosis.

We have demonstrated the feasibility of using adenovirusderived vectors for in vivo delivery of a drug resistance Sh ble gene. The intranasal droplet inhalation technique was chosen because it causes less trauma and avoids the mortality associated with surgical exposure in the intratracheal administration. In previous anti-EBV vaccination studies performed in cottontop tamarin monkeys with recombinant adenoviral vectors using the i.n. route, we showed by PCR that adenovirus vector DNA was found in several organs (51). Pathological examination of the organs revealed no virus-mediated toxic effects to the lungs or other organs. In the present study, we did not observe any specific toxicity in the organs either at autopsy, or by histochemical examination of the frozen sections (not shown). All our experiments were performed with E1-deleted recombinant adenoviral vectors that have proven to be useful tools in transferring genes to numerous organs in vivo (27-32). However, their application is presently limited because of the lack of persistent gene expression, and the elicited antivector cellular immunity (52). This limitation will hopefully be circumvented by the improvement of the future generation of adenoviral vectors that avoid immune suppression (29).

In experiments using B16 melanoma grafted into syngeneic C57BL/6 mice, we have addressed the question of whether expression of BRP in mouse lungs would affect the antitumor activity of bleomycin. After treatement of mice with Ad.CMVble and bleomycin, we observed that the efficacy of bleomycin to inhibit tumor growth was not impaired. Local pulmonary expression of BRP elicited lung protection to bleomycin-induced lung injury, as evaluated by the absence of lung lesions and lung collagen deposition (Tran, P.L., manuscript in preparation).

In conclusion, it is clear that expression of BRP might be a helpful tool for the protection of bleomycin-induced lung damage. Further experiments will be necessary to define the modalities of use of Sh ble transfer as a new approach for preven- 
tion of lung fibrosis. Finally, the benefit of this approach will be balanced with the potential risk of using adenovirus vectors in immunocompromised cancer patients.

\section{Acknowledgments}

We thank E. Faure and M. Stanciu and the Laboratoire d'Expérimentation Animale (Institut Gustave Roussy) for their expert help with animal procedures, the Laboratoire d'Histologie C (Institut Gustave Roussy) for their advice and facilities in preparation of paraffin-embedded samples and staining, D. Urbain for technical assistance, and N. Difalco for preparation of the cryosections. Dr. B. Nalpas (Laboratoire d'Hépatologie, Hopital Necker) is thanked for performing statistic analysis. We also thank T. Ragot, Dr. P. Lemarchand, Dr. B. Maître, and Professor C. Brechot for critical review of this manuscript.

\section{References}

1. Cooper, J.A., A.C. White, and R.A. Matthay. 1986. Drug-induced pulmonary disease. Part I: cytotoxic drugs. Am. Rev. Resp. Dis. 133:321-340.

2. Umezawa, T., H. Takeuchi, and Y. Okami. 1966. New antibiotics, bleomycin A and B. J. Antibiot. (Tokyo). 19:200-209.

3. Ichikawa, T., I. Nakano, and I. Hirokawa. 1969. Bleomycin treatment of tumors of the penis and scrotum. J. Urol. 102:699-703.

4. Blum, R.H., S.K. Carter, and K. Agree. 1973. A clinical review of bleomycin: a new antineoplastic agent. Cancer. 31:903-914.

5. Hussar, D.A. 1974. New drugs of 1973. Am. J. Pharm. Sci. Supporting Public Health. 146:37-58.

6. Bennett, J.M., and S.D. Reich. 1979. Bleomycin. Ann. Intern. Med. 90: 945-948.

7. Muggia, F.M., A.C. Louie, and B.I. Sikic. 1983. Pulmonary toxicity of antitumor agents. Cancer Treat. Rep. 10:221-243.

8. Bedrossian, C.W.M., M.A. Lunda, B. Mackay, and B. Lichtiger. 1973. Ultrastructure of pulmonary bleomycin toxicity. Cancer (Phila.). 32:44-51.

9. Adamson, I.Y.R., and P.H. Bowden. 1974. The pathogenesis of bleomycin-induced pulmonary fibrosis in mice. Am. J. Pathol. 77:185-196.

10. Colby, T.V., and A.C. Churg. 1986. Patterns of pulmonary fibrosis. Pathol. Аппи. 21:277-309.

11. Bitterman, P.B., S.I. Rennard, S. Adelberg, and R.G. Crystal. 1983. Role of fibronectin as a growth factor for fibroblasts. J. Cell Biol. 97:1925-1932.

12. Hoyt, D.G., and J.S. Lazo. 1988. Alterations in pulmonary mRNA encoding procollagens, fibronectin and transforming growth factor-beta precede bleomycin-induced pulmonary fibrosis in mice. J. Pharmacol. Exp. Ther. 246: $765-771$.

13. Kovacs, E., and J. Kelley. 1986. Intra-alveolar release of a competencetype growth factor after lung injury. Am. Rev. Respir. Dis. 133:68-72.

14. Reiser, K.M., and J.A. Last. 1986. Early cellular events in pulmonary fibrosis. Exp. Lung Res. 10:331-355.

15. Kovacs, E.J. 1991. Fibrogenic cytokines: the role of immune mediators in the development of scar tissue. Immunol. Today. 12:17-23.

16. King, S.L., A.C. Lichtler, D.W. Rowe, W. Xie, G.L. Long, M.P. Absher, and K.R. Cutroneo. 1994. Bleomycin stimulates Pro-1(I) collagen promoter through transforming growth factor response element by intracellular and extracellular signaling. J. Biol. Chem. 269:13156-13161.

17. Lazo, J.S., and C.J. Humphreys. 1983. Lack of metabolism as the biochemical basis of bleomycin-induced pulmonary toxicity. Proc. Natl. Acad. Sci. USA. 80:3064-3068.

18. Piguet, P.F., H. Rosen, C. Vesin, and G.E. Grau. 1993. Effective treatment of the pulmonary fibrosis elicited in mice by bleomycin or silica with antiCD-11 antibodies. Am. Rev. Respir. Dis. 147:435-441.

19. Giri, S.N., D.M. Hyde, and MA. Hollinger. 1993. Effect of antibody to transforming growth factor- $\beta$ on bleomycin induced accumulation of lung collagen in mice. Thorax. 48:959-966.

20. Piguet, P.F., and C. Vesin. 1994. Treatment by human recombinant soluble TNF receptor of pulmonary fibrosis induced by bleomycin or silica in mice. Eur. Respir. J. 7:515-518

21. Drocourt, D., T. Calmels, J.P. Reynes, M. Baron, and G. Tiraby. 1990. Cassettes of the Streptoalloteichus hindustanus ble gene for transformation of lower and higher eukaryotes to phleomycin resistance. Nucleic Acid Res. 18: 4009.

22. Gatignol, A.H., H. Durand, and G. Tiraby. 1988. Bleomycin resistance conferred by a drug binding protein. FEBS Lett. 230:171-175.

23. Dumas, P., M. Bergdoll, C. Cagnon, and J.M. Masson. 1994. Crystal structure and site-directed mutagenesis of a bleomycin resistance protein and their significance for drug sequestering. EMBO (Eur. Mol Biol. Organ.) J. 13: 2483-2492.
24. Weinbach J., A. Camus, J. Bara, P. Dumont, M. Julian, S. Cros, C. Babinet, and G. Tiraby. 1996. Transgenic mice expressing the Sh ble bleomycin-resistance gene are protected against bleomycin-induced pulmonary fibrosis. Cancer Res. In press.

25. Van Doren, K., and Y. Gluzman. 1984. Efficient transformation of human fibroblastics by adenovirus-simian 40 recombinants. Mol. Cell. Biol. 4 1653-1656.

26. Van Doren, K., D. Hanahan, and Y. Gluzman. 1984. Infection of eucaryotic cells by helper-independent recombinant adenovirus: early region 1 is not obligatory for integration of viral DNA. J. Virol. 50:606-614.

27. Stratford-Perricaudet, L.D., M. Levrero, J.F. Chasse, M. Perricaudet, and P. Briand. 1990. Evaluation of the transfer and expression in mice of an enzyme-encoding gene using a human adenovirus vector. Hum. Gene Ther. 1: 241-256.

28. Rosenfeld, M.A., K. Yoshimura, B.C. Trapnell, K. Yoneyama, E.R. Rosenthal, W. Dalemans, M. Fukayama. J. Bargon, L.E. Stier, L.D. StratfordPerricaudet, et al. 1992. In vivo transfer of the human cystic fibrosis transmembrane conductance regulator gene to the airway epithelium. Cell. 68:143-155.

29. Kremer, E.J., and M. Perricaudet. 1995. Adenovirus and adeno-associated virus mediated gene transfer. Br. Med. Bull. 51:31-44.

30. Jaffe, H.A., C. Danel, G. Longenecker, M. Metzger, Y. Setoguchi, M.A Rosenfeld, T.W. Gant, S.S. Thorgeirsson, L.D. Stratford-Perricaudet, M. Perricaudet, et al. 1992. Hepatic gene transfer therapy: replication deficient, recombinant adenovirus-mediated in vivo gene transfer and expression in normal rat liver. Nat. Genet. 1:372-384.

31. Ragot, T., N. Vincent, P. Chafey, E. Vigne, H. Gilgenkrantz, D. Couton, J. Cartaud, P. Briand, J.C. Kaplan, M. Perricaudet, and A. Kahn. 1993. Efficien adenovirus-mediated transfer of a human minidystrophin gene to skeletal muscle of $m d x$ mice. Nature (Lond.). 361:647-650.

32. Herz, J., and R.D. Gerard. 1993. Adenovirus-mediated transfer of low lipoprotein receptor gene accurately accelerates cholesterol clearance in normal mice. Proc. Natl. Acad. Sci. USA. 90:2812-2816.

33. Shenks, T., and J. Williams. 1984. Genetics analysis of adenoviruses. Curr. Top. Microbiol. Immunol. 111:1-39.

34. Graham, F.L., J. Smiley, W.C. Russel, and R. Nairn. 1977. Characteristics of a human cell line transformed by DNA from adenovirus type 5. J. Gen. Virol. 36:59-72.

35. Mulsant, P., A. Gatignol, M. Dalens, and G. Tiraby. 1988. Phleomycin resistance as a dominant selectable marker in $\mathrm{CHO}$ cells. Somatic Cell Mol. Genet. 14:243-252.

36. Stratford-Perricaudet, L.D., I. Makeh, M. Perricaudet, and P. Briand. 1992. Widespread long-term gene transfer to mouse skeletal muscles and heart J. Clin. Invest. 90:626-630.

37. Laemmli, U.K. 1970. Cleavage of structural proteins during the assembly of the head of bacteriophage T4. Nature (Lond.). 227:680-685.

38. Tran, P.L., and M.A. Deugnier. 1985. Intracellular localization of 12-O3-N-dansylamino TPA in C3H/10T1/2 mouse cell line. Carcinogenesis (Oxf.). 6 : 433-439.

39. Raap, A.K., M.P.C. van de Corput, R.A.W. Vervenne, van R.P.M Gijlswijk, H.J. Tanke, and J. Wiegant. 1995. Ultra-sensitive FISH using peroxidase-mediated deposition of biotin- or fluorochrome tyramides. Hum. Mol. Genet. 4:529-534.

40. Linares-Cruz, G., G. Millot, P. De Cremoux, J. Vassy, B. Olofsson, J.P. Rigaut, and F. Calvo. 1995. Combined analysis of in situ hybridization, cell cycle and structural markers using reflectance and immunofluorescence confocal microscopy. Histochem. J. 27:15-23.

41. Harrison, J.H., and J.S. Lazo. 1987. High dose continuous infusion of bleomycin in mice: a new model for drug-induced pulmonary fibrosis. J. Pharmacol. Exp. Ther. 243:1185-1194.

42. Tran, P.L., M. Grouselle, D. Georgescauld, and M.J. Brienne. 1991. Direct visualization by fluorescence video microscopy of the subcellular localization of a new derivative phorbol-12,13-dibutanoate. Cell. Physiol. Biochem. 1: $31-45$

43. Calmels, T.P.G., J.S. Mistry, S.C. Watkins, P.D. Robbins, R. McGuire, and J.S. Lazo. 1993. Nuclear localization of bacterial Streptoalloteichus hindustanus bleomycin resistance protein in mammalian cells. Mol. Pharmacol. 44: 1135-1141.

44. Dong, J.Y., D. Wang, F.W. Van Ginkel, D.W. Pascual, and R.A. Frizzell. 1996. Systematic analysis of repeated gene delivery into animal lungs with a recombinant adenovirus vector. Hum. Gene Ther. 7:319-331.

45. Lazo, J.S. 1981. Angiotensin converting enzyme in mice during subacute bleomycin administration. Toxicol. Appl. Pharmacol. 59:395-404.

46. Collins, J.F., B. McCullough, J.J. Coalson, and W.G. Johanson. 1981 Bleomycin-induced diffuse interstitial pulmonary fibrosis in baboons. Am. Rev. Respir. Dis. 123:305-312.

47. Brody, S.L., M. Metzger, C. Danel, M.A. Rosenfeld, and R.G. Crystal. 1994. Acute responses of non-human primates to airway delivery of an adenovirus vector containing the human cystic fibrosis transmembrane conductance regulator cDNA. Hum. Gene Ther. 5:821-836.

48. Quinones, F., and E. Crouch. 1986. Biosynthesis of interstitial and basement membrane collagens in pulmonary fibrosis. Am. Rev. Respir. Dis. 134: 1163-1171. 
49. Moseley, P.L., C. Hemken, and G.W. Hunninghake. 1986. Augmentation of fibroblast proliferation by bleomycin. J. Clin. Invest. 78:1150-1154.

50. Lazo, J.S., D.G. Hoyt, S.M. Sebti, and B.R. Pitt. 1990. Bleomycin: a pharmacological tool in the study of the pathogenesis of interstitial pulmonary fibrosis. Pharmacol. Ther. 47:347-358.

51. Tran, P.L., T. Ragot, P.E. Watkins, A.J. Morgan, and M. Perricaudet. 1992. Detection by PCR of the gp-340-expressing recombinant adenovirus
(Ad) DNA and transcripts in tissues of cottontop tamarins vaccinated against EBV-induced lymphomas. Vth International Symposium on Epstein-Barr Virus and Associated Diseases. 144:P.V.8. (Abstr.)

52. Kass-Eisler, A., E. Falck-Pedersen, D.H. Elfenbein, M. Alvira, P.M. Buttrick, and L.A. Leinwand. 1994. The impact on developmental stage, route of administration and the immune system on adenovirus-mediated gene transfer. Gene Ther. 1:395-402. 